University of Wollongong

Research Online

Faculty of Engineering and Information

Faculty of Engineering and Information

Sciences - Papers: Part A

Sciences

$1-1-2012$

\title{
Effect of manganese content and microstructure on the susceptibility of X70 pipeline steel to hydrogen cracking
}

D Hejazi

University of Wollongong, dh712@uowmail.edu.au

A J. Haq

University Of Wollongong, ayesha@uow.edu.au

$\mathrm{N}$ Yazdipour

University Of Wollongong, nimayaz@uow.edu.au

D P. Dunne

University of Wollongong, druce@uow.edu.au

A Calka

University of Wollongong, acalka@uow.edu.au

See next page for additional authors

Follow this and additional works at: https://ro.uow.edu.au/eispapers

Part of the Engineering Commons, and the Science and Technology Studies Commons

Research Online is the open access institutional repository for the University of Wollongong. For further information contact the UOW Library: research-pubs@uow.edu.au 


\title{
Effect of manganese content and microstructure on the susceptibility of X70 pipeline steel to hydrogen cracking
}

\begin{abstract}
The influence of composition and microstructure on susceptibility to hydrogen induced cracking (HIC) was investigated in high strength pipeline steels, with Mn contents of $1.2 \%$ (standard, X70), and $0.5 \%$ (medium, MX70). The HIC resistance of the simulated coarse grained heat affected zone microstructures and normalized X70 transfer bar was also investigated. Notched and fatigue pre-cracked samples were charged with hydrogen prior to three point bend tests. The conditional fracture toughness JQ was determined. The results are discussed in relation to grain size, microstructure, composition and the type and distribution of non-metallic inclusions and precipitates.
\end{abstract}

\section{Keywords}

susceptibility, $x 70$, effect, pipeline, manganese, steel, hydrogen, cracking, content, microstructure

Disciplines

Engineering | Science and Technology Studies

\section{Publication Details}

Hejazi, D., Haq, A. J., Yazdipour, N., Dunne, D. P., Calka, A., Barbaro, F. J. \& Pereloma, E. V. (2012). Effect of manganese content and microstructure on the susceptibility of $X 70$ pipeline steel to hydrogen cracking. Materials Science and Engineering A: Structural Materials: Properties, Microstructure and Processing, 551 (August 15), 40-49.

\section{Authors}

D Hejazi, A J. Haq, N Yazdipour, D P. Dunne, A Calka, Frank J. Barbaro, and E V. Pereloma 


\section{SUSCEPTIBILITY OF LOW AND HIGH MANGANESE X70 PIPELINE STEEL TO HYDROGEN EMBRITTLEMENT}

D. Hejazi ${ }^{1, a}$, A.J. Haq ${ }^{1, b}$, N. Yazdipour ${ }^{1, c}$, D.P. Dunne ${ }^{1, d}$, A. Calka, ${ }^{1, e}$, F. Barbarro ${ }^{2, f}$, E.V. Pereloma ${ }^{1, g}$,

${ }^{1}$ School of Mechanical, Materials \& Mechatronic Engineering, University of Wollongong, Wollongong NSW 2522 Australia

${ }^{2}$ BlueScope Steel Limited Five Islands Rd Port Kembla NSW 2505, Australia

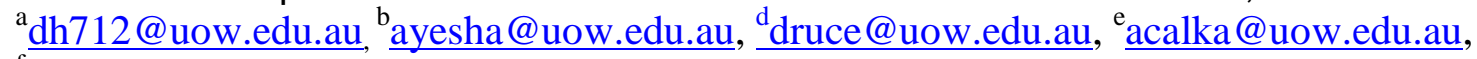
ffrank.barbaro@bluescopesteel.com, ${ }^{\mathrm{g}}$ elenap @uow.edu.au

Keywords: pipeline steel, microstructure, hydrogen charging, fracture toughness, fractography 


\begin{abstract}
Hydrogen, even in very low concentrations, can diffuse to regions of high stress concentration resulting in a degradation of mechanical properties. However, the transport of hydrogen depends on the interaction between hydrogen atoms and microstructural traps which, in turn, is related to microstructure. The influence of composition and microstructure on susceptibility to hydrogen embrittlement was investigated by selecting pipeline steels with different Mn contents, i.e., standard Mn (X70) and medium Mn (MX70) strips. The HAZ (heat affected zone) microstructures of these strips as well as a normlised transfer bar (TB) were also investigated. HAZ simulations were conducted using Gleeble thermo-mechanical machine to simulate a thermal cycle typical of inservice repairs. Notched and fatigue pre-cracked samples were subjected to electrochemical hydrogen charging using a solution of $\mathrm{H}_{2} \mathrm{SO}_{4}$ and $\mathrm{NaAsO}_{2}$ to achieve 2 and 4 ppm hydrogen content. Three point bend tests were conducted on as-received and hydrogen-charged samples. The X70 strip exhibited a higher $\mathrm{J}_{\mathrm{Q}}$ than the $\mathrm{MX70}$ strip before and after charging, whereas the TB displayed the lowest $\mathrm{J}_{\mathrm{Q}}$. The fracture performance of both steels deteriorated almost linearly with an increase in the hydrogen content. Because of their coarser prior austenite grain sizes and the presence of relatively hard bainitic-ferrite structure with martensite/austenite islands, the simulated HAZ microstructures of the two steels demonstrated significantly lower fracture resistance both with and without hydrogen. The results obtained were compared and discussed in relation to the grain size, microstructure, composition and the type and distribution of precipitates in the samples.
\end{abstract}




\section{Introduction}

Over the last twenty years in Australia the standard gas pipeline grade has moved from $\mathrm{X} 52$ through to the present $\mathrm{X} 70$ with the maximum operating pressure rising from 6.8 $\mathrm{MPa}$ to $15.3 \mathrm{MPa}$. This trend has been motivated by the economical benefits of higher strength pipelines which can result in smaller diameter, thinner walled pipes and consequently reduced welding cost, pipe transport-to-site costs and eventually gas transportation costs[1]. Hydrogen is a common contaminant to pipeline steels, due to environmental exposure and particularly as a result of girth welding, X70 is known to be susceptible to hydrogen induced cracking (HIC) due to hydrogen absorption [2].

When a steel pipeline is exposed to an acidic environment, its surface corrodes and produces hydrogen. In the case of sour gas, the presence of $\mathrm{H}_{2} \mathrm{~S}$ can retard the recombination of hydrogen atoms to form hydrogen molecules, allowing hydrogen atoms to enter the steel. The adsorbed hydrogen atoms diffuse to tri-axial stress zones and become trapped at sensitive microstructural features such as hard phases and the interface between non-metallic inclusions and the steel matrix [3-4]. If the trapped hydrogen reaches the critical value necessary for crack initiation, HIC can take place. The absorbed hydrogen atoms can also recombine to form molecules at defect sites such as voids, inclusions, grain boundaries and dislocations, resulting in pressure build up that can lead to cracking [5].

The relationship between HIC of steels and the presence of metallurgical micro-defects can be understood in terms of various models that have been proposed, which are based on the fact that the defects act as hydrogen-trapping sites to accumulate hydrogen locally[6]. Several kinds of structural features can act as traps: e.g., grain boundaries, microvoids, dislocations and non-metallic inclusions or interfaces between the metal and a second phase (ferrite - carbide interface) [7]. These traps can be reversible or irreversible depending on their binding energy for hydrogen atoms. Grain boundaries and dislocations are weak traps with low binding energies. On the other hand, the interfaces of non-metallic inclusions such as $\mathrm{MnS}$, oxides and oxysulphides of $\mathrm{Al}$ and $\mathrm{Ca}$, and precipitates like $\mathrm{TiC}$ are considered to be strong irreversible traps for hydrogen at normal service temperatures $[2,8-10]$. Types of inclusions and precipitates that have been 
identified in pipeline steels are $\mathrm{Al}_{2} \mathrm{O}_{3}$, complex oxides of $\mathrm{Al}-\mathrm{Ca}-\mathrm{Si}-\mathrm{O}$, oxides and oxysulphides of $\mathrm{Ca}$ and $\mathrm{Al}$, oxides of $\mathrm{Mg}$ and $\mathrm{Mn}$, spinel type double oxide $\mathrm{FeO} \mathrm{Al}_{2} \mathrm{O}_{3}$, titanium oxide, ferric carbide, $\mathrm{MnS}$ and complex (Fe, Mn)S and nitrides and carbonitrides of $\mathrm{Ti}$ and $\mathrm{Nb}[2-4,6,11-16]$. Large inclusions such as elongated $\mathrm{MnS}$ and clusters or stringers of oxides have been reported to increase the susceptibility of steels to HIC [17].

The steel microstructure also plays an important role in HIC. In the thermo-mechanically controlled processing (TMCP) of pipeline steels, different combinations of microstructures can be obtained, such as ferrite-pearlite, bainitic ferrite, bainitic ferritebainite, polygonal ferrite-bainitic ferrite etc [18-19]. It has been reported that the efficiency of trapping tends to increase in the following order: small second phase particles, coarse pearlite, fine pearlite, bainite, martensite and acicular ferrite[15, 20]. Huang reported that microstructures containing granular bainite with martensite/austenite (M/A) microconstituent increase the susceptibility to HIC. On the other hand, bainitic ferrite with M/A interlayers is known to be one of the most desirable microstructures due to its high strength and good toughness and can be obtained by optimization of process parameters, without the need for significant concentrations of alloying elements. Bainitic ferrite, formed by mixed diffusion and shear transformation mode has a high dislocation density [21-25].

It has been shown that the presence of $\mathrm{Mn}$ in amounts greater than $1 \mathrm{wt}$ \% increases the susceptibility of steel to HIC, but quench-tempering treatment can remove the detrimental effect of Mn [26]. In recent years, there have been attempts to shift to lower Mn levels, in the range of $0.2-0.5 \%$ to reduce susceptibility to HIC, as well as decreasing centerline microstructural banding [27]. Further, decreasing the Mn content can also reduce the reliance on relatively expensive steelmaking practices that are required to produce steels with ultra low S levels. At these lower levels of $\mathrm{Mn}$ and at a given $\mathrm{S}$ level, formation of $\mathrm{MnS}$ from the liquid will take place closer to the solidification temperature and thus be of a smaller size [28]. Since the plasticity of $\mathrm{MnS}$ inclusions in the hot rolling process increases directly with increasing Mn level, lowering the Mn levels should reduce the tendency of the smaller size inclusions to deform, thereby reducing the aspect ratio of $\mathrm{MnS}$ inclusions in the final product. It is well known that elongated MnS inclusions can 
have a detrimental effect on the fracture toughness of both the pipe body and the weld line. In conventional high $\mathrm{Mn}$ steels, the above mentioned effects of elongated MnS inclusions have generally been controlled by use of low S levels and the sulphide shape controlling additions of $\mathrm{Ca}[1]$.

Although shifting to lower Mn levels appears to have several advantages, the steel strength will be compromised in the absence of compensation by increasing the levels of $\mathrm{C}, \mathrm{N}$ and microalloying elements. Moreover, a Mn content greater than $0.3 \%$ in pipeline steels has been reported to cause hydrogen induced blister cracking on being subjected to a sour gas environment [29].

This study had the aim of investigating the effect of microstructure and composition on hydrogen embrittlement of X70 pipeline steels with standard (1.2 wt. \%) and medium ( 0.5 wt. \%) Mn contents, by using a combination of cathodic hydrogen charging ( 2 and 4 ppm), three-point bend tests (TPB) and microstructural characterization. Pipeline steels containing the standard and medium concentrations of Mn were compared for HIC resistance. Additionally, the heat affected zone (HAZ) microstructure produced by welding was simulated and tested to compare the results with those of the hot rolled (parent) samples.

\section{Experimental}

Standard and medium Mn X70 grade pipeline steel (X70 and MX70 respectively) were used in this investigation. Samples were taken from the transfer bar (TB) and hot rolled strips produced by BlueScope steel Ltd. The chemical compositions of the steels are listed in Table 1. TB samples from the X70 steel were normalised in an argon atmosphere at $950^{\circ} \mathrm{C}$ for 20 minutes to homogenize the structure.

The coarse grained HAZ (CGHAZ) structure produced by in-service pipeline welding was simulated using a Gleeble 3500 thermomechanical simulator. The samples were subjected to rapid heating and cooling schedules as shown in Fig. 1. The simulation was aimed to achieve a cooling time of 3 seconds between $800^{\circ} \mathrm{C}$ to $500^{\circ} \mathrm{C}\left(\mathrm{t}_{8 \rightarrow 5}\right)$. Highpressure Ar gas was used for cooling. The microstructures of the simulated samples were 
comparable to those of the HAZ produced by in-service welding at a low heat input. The hardness of the steels were characterized using INDENTEC Vickers micro hardness machine.

Samples of dimensions $5 \mathrm{~mm} \times 5 \mathrm{~mm} \times 25 \mathrm{~mm}$ were taken parallel to the rolling direction and were wire cut to obtain a $1 \mathrm{~mm}$ deep, $0.3 \mathrm{~mm}$ wide notch. The notched samples were then subjected to fatigue precracking on an Instron 1341 machine. The Syncrack software (Syncrack Version 1 developed by Arthur Carlton Synapse Technology Pty Ltd) was employed to carry out cyclic loading. The loads used for pre-cracking were a fraction of the load $\mathrm{P}_{\mathrm{L}}$ which is a function of yield strength and is given by Eq. 1 [30]

$$
P_{L}=\left[\left(\frac{4}{3}\right)\left(\frac{B b_{0}{ }^{2} \sigma_{Y}}{S}\right)\right]
$$

where $\mathrm{B}, \mathrm{b}_{0}, \mathrm{~S}$ and $\sigma_{\mathrm{y}}$ are effective thickness, original uncracked ligament, span and effective yield strength, respectively. To obtain a fatigue crack of $1.5 \mathrm{~mm}$ depth, maximum loads of $850 \mathrm{~N}$ and $1350 \mathrm{~N}$ were applied for the as-received and HAZ samples respectively. The stress ratio and cycling frequency were 0.4 and $50 \mathrm{~Hz}$ respectively. A range of 50,000 to 100,000 cycles was used for each specimen [31].

Electrochemical charging was performed within one hour of fatigue pre-cracking to ensure that the charging was carried out on fresh surfaces. Cathodic hydrogen charging of the samples at a current density of $50 \mathrm{~mA} / \mathrm{cm}^{2}$ was performed in $0.5 \mathrm{~N} \mathrm{H}_{2} \mathrm{SO}_{4}$ with 250 $\mathrm{mg} / \mathrm{L}$ of $\mathrm{NaAsO}_{2}$ as a recombination poison. Calibration curves were obtained by charging the samples for different times. To prevent the loss of hydrogen, the samples were stored in liquid nitrogen immediately after cathodic charging. The amount of hydrogen charged was measured by hot extraction using Eltra ONH-2000 [32] at BlueScope Steel Ltd. The calibration curve showed that 20 and 90 minutes of charging were required to introduce 2 and 4 ppm of hydrogen, respectively. 
In order to minimize hydrogen loss TPB tests were conducted using a Instron 5566 machine within 10 minutes of charging. The samples were subjected to a series of loading-unloading cycles and load vs. load line displacement curves were obtained. Crack extension was calculated from the load line displacement as follows (Eq. 2):

$$
a=W \times\left(0.997-3.58 U-1.51 U^{2}-110 U^{3}+1232 U^{4}-4400 U^{5}\right)
$$

where, $a$ is the crack length, $W$ is the sample width and $U$ is given by Eq. 3 .

$$
U=\frac{1}{(1+\sqrt{E B \delta / F})}
$$

where, $\delta, E, B$ and $F$ are crack opening displacement, the elastic modulus, sample thickness and the applied load respectively. The data collected by a digital camera during the TPB tests were used to measure $\delta$. The $\mathrm{J}$ integral versus crack extension curves were obtained in accordance with the method specified in ASTM E813-89 [30] and the conditional value of fracture toughness, $\mathrm{J}_{\mathrm{Q}}$, was calculated.

The microstructures of all samples were characterised using standard optical metallography techniques. Energy dispersive x-ray spectroscopy (EDS) analysis of the samples was carried out using a JEOL JSM-7001F field emission gun scanning electron microscope (FEGSEM). To analyse the type and distribution of inclusions and precipitates, automated electron beam particle analyser software, Esprit Steel (Bruker, Germany), was employed. An area of $5 \mathrm{~mm} \times 2 \mathrm{~mm}$ of each sample was scanned. After the TPB test, the fracture surfaces of the samples were examined using a JEOL JSM 6490LV SEM in a region within $1 \mathrm{~mm}$ of the crack extension. 


\section{Results}

\subsection{As received material characterisation}

\subsubsection{Optical metallography and Precipitate characterization}

Fig. 2 shows optical micrographs of the studied samples. The normalised TB (Fig. 2a) exhibited a ferrite-pearlite microstructure with an average grain size of $14 \pm 0.5 \mu \mathrm{m}$. Although the X70 and MX70 strips also showed ferrite-pearlite microstructures, the grains were slightly elongated along the rolling direction. The average sizes of the ferrite grains were $10 \pm 0.8$ and $11 \pm 0.6$ respectively in the X70 and MX70 strips. The volume percentage of pearlite was determined to be $12 \pm 1,9 \pm 0.8$, and $11 \pm 1$ respectively in the TB, X70 and MX70 samples. The simulated HAZ of the X70 and MX70 strips consisted of mainly bainitic-ferrite microstructure that formed from coarse-grained austenite.

The number of the precipitate particles per square micron in the MX70 strip was found to be the significantly higher at 0.77 per $\mu \mathrm{m}^{2}$ as compared to 0.38 per $\mu \mathrm{m}^{2}$ in the X70 strip. Therefore, in terms of density of inclusions/precipitates, the standard X70 was much "cleaner" than the medium Mn version. The results of the EDS microanalysis of the precipitates are shown in Fig. 3, which is a plot of the number of the different types of precipitates detected in the test area for the two steels. A striking difference that can be observed from this plot is that the most frequently occurring precipitates in the MX70 strip are nitrides followed by oxides and sulphides. Most of these nitrides were complex $(\mathrm{Ti}, \mathrm{Nb})(\mathrm{C}, \mathrm{N})$ precipitates. On the other hand, the X70 strip showed a much lower number of nitrides (more than an order of magnitude lower than MX70). This is a result of compositional differences between the two steels, i.e., the higher Ti, $\mathrm{C}$ and $\mathrm{N}$ contents of the MX70 steel produce a significantly larger fraction of carbonitride precipitates. The number of sulphide inclusions per unit area, and in particular, $\mathrm{MnS}$ and complex $\mathrm{MnS}$, was almost the same in the two steels. However, the number of oxides in the MX70 strip was double that observed in the X70 strip. These oxide inclusions usually contained $\mathrm{Fe}$, $\mathrm{Ca}, \mathrm{Al}, \mathrm{Mg}$ and $\mathrm{Mn}$, and a small amount of Ti was present in about 50 percent of these precipitates. 
Mean size and size distributions of the $(\mathrm{Ti}, \mathrm{Nb})(\mathrm{C}, \mathrm{N})$ precipitates, oxides of $\mathrm{Ca}$ and $\mathrm{Al}$, and the aspect ratio of $\mathrm{MnS}$ precipitates in the two steels are shown in Fig. 4. The $(\mathrm{Ti}, \mathrm{Nb})(\mathrm{C}, \mathrm{N})$ precipitates in MX70 strip exhibited a unimodal distribution with an average diameter of $0.8 \pm 0.8 \mu \mathrm{m}$. The size distribution of the precipitates was very broad with a long tail (not shown in the figure) with some precipitates having diameters in the range 3-5 $\mu \mathrm{m}$. On the other hand the X70 strip appeared to show a bimodal distribution with mean sizes of $0.6 \pm 0.2$ and $2 \pm 0.3 \mu \mathrm{m}$. However, it must be noted that, the number density of the nitrides in the MX70 sample was significantly higher than in the X70 strip. The mean aspect ratio and the distribution of MnS precipitates in the MX70 strip were larger and broader than those in the X70 strip. The distribution of aspect ratios of $\mathrm{MnS}$ particles in the MX70 strip had a long tail with some of the precipitates having aspect ratios up to 20:1. The mean aspect ratios were $7 \pm 5$ and 3.2 \pm 2 in MX70 and X70 strips, respectively. The average sizes of the $\mathrm{Ca}$ and $\mathrm{Al}$ oxide precipitates in the $\mathrm{X} 70$ and MX 70 strips were similar: $3.6 \pm 3.8 \mu \mathrm{m}$ and $3.8 \pm 2.6 \mu \mathrm{m}$ respectively. The standard deviations in the average values of the aspect ratios of $\mathrm{MnS}$ precipitates and the diameters of oxide inclusions are relatively high compared to the carbonitrides since there were relatively few particles and there was a considerable spread of particle sizes.

\subsubsection{Hardness profile}

Fig. 5 shows the macro-hardness of profiles of the two steels after HAZ simulation. The gradients indicate that the simulated CGHAZ extended over a distance of about $\pm 10 \mathrm{~mm}$ from the sample centre. The approximately constant hardness of the CGHAZ was about $265 \mathrm{HV}$ for X70 and $222 \mathrm{HV}$ for MX70, indicating that the X70 had a significantly higher hardenability than the MX70 steel. As expected, the CGHAZ region exhibited higher hardness than the base metal: $\Delta \mathrm{H} \sim 50 \mathrm{HV}$ points for $\mathrm{X} 70$ and about $20 \mathrm{HV}$ points for MX70. In the hot rolled condition the X70 was about $10 \mathrm{HV}$ points higher than MX70. Li et al. [8]reported a similar simulated HAZ hardness of $238 \mathrm{HV}$ for X70 grade steel the same peak temperature used in the present investigation $\left(1350{ }^{\circ} \mathrm{C}\right)$ and a similar $\Delta \mathrm{t}_{8 \rightarrow 5}(4 \mathrm{~s}$ compared to $3 \mathrm{~s}$ ). The alloy composition was: $0.05 \mathrm{C} 0.26 \mathrm{Si} 1.48 \mathrm{Mn}, 0.17 \mathrm{Mo}$, $0.05 \mathrm{Nb}\left(\mathrm{C}_{\mathrm{E}}=0.404\right)$. 


\subsection{Three point bend test:}

Figs. 6 and 7 show the J-Resistance (J-R) curves (J-based fracture resistance curves) for all samples before and after hydrogen charging. The calculated $J_{Q}$ values are given in Table 2 and are plotted in Fig 8. Fig. 6 and Fig. 8 show that for X70 samples, the hot rolled strip exhibited the highest toughness followed by the normalised TB and simulated HAZ samples. The $J_{Q}$ value of the HAZ structure was significantly lower than that of the hot rolled strip. All samples show loss of toughness after hydrogen charging, with the $\mathrm{J}_{\mathrm{Q}}$ decreasing almost linearly with increasing hydrogen content. The extent of the reduction in $\mathrm{J}_{\mathrm{Q}}$ on charging was almost the same for the normalised TB and the X70 strip for 2 ppm $\mathrm{H}$ with gradients of $\sim 18.5$ and $\sim 19.5 \mathrm{kPa} . \mathrm{m}$ per ppm $\mathrm{H}$, respectively. However, on charging to $4 \mathrm{ppm} \mathrm{H}$, the strip shows a higher reduction compared to the TB. The HAZ sample showed a slightly larger reduction for both 2 and $4 \mathrm{ppm} \mathrm{H}$.

Comparison of the $\mathrm{J}_{\mathrm{Q}}$ values for the standard and medium Mn strips (Fig. 7a with Fig. 6a and Fig. 8) shows that the uncharged hot rolled MX70 strip displayed a lower toughness than the uncharged X70 strip. Moreover, the toughness of the hot rolled MX70 strip decreased linearly with an increase in hydrogen content, similar to the X70 strip. Furthermore, the extent of the reduction in toughness observed on charging is almost the same for both the strips in the hot rolled condition, with the MX70 strip having a slightly lower gradient of $19.25 \mathrm{kPa} . \mathrm{m}$ per ppm $\mathrm{H}$. These observations, therefore, indicate that the hot rolled X70 strip exhibits consistently better fracture performance than the MX70 strip both before and after hydrogen charging.

The simulated HAZ structure of the MX70 strip again displays a significantly lower toughness than the hot rolled strip. Moreover, it is also clear from Fig. 8 that, $\mathrm{J}_{\mathrm{Q}}$ values for the simulated HAZ structures of the X70 and MX70 steels were very similar both in the charged and uncharged conditions with the MX70 steels showing slightly higher $\mathrm{J}_{\mathrm{Q}}$ values. Therefore, these results demonstrate that there is a significant reduction in the toughness of the X70 alloys when the structure changes from fine grained ferrite-pearlite to coarse grained bainitic ferrite with martensite-austenite islands. Similar results have been reported in literature[33-37]. 


\subsection{Fractography:}

SEM images of fracture surfaces of the normalised TB and the two hot rolled X70 strips before and after charging are depicted in Fig. 9. All the uncharged samples exhibited features characteristic of ductile fracture, such as dimples and microvoids as reported in literature [7, 38-39]. Both the hot rolled X70 and MX70 strips exhibited a combination of dimples and microvoids, whereas the normalised TB sample revealed only elongated dimples without any microvoids. The micrograph of the fracture surface of MX70 strip gives an example of an inclusion within a shear/tear dimple.

On charging with 2ppm hydrogen, the TB and X70 strip specimens showed a mixed mode or quasi-cleavage fracture, but with cleavage dominating in the case of TB and elongated dimples without microvoids being a significant feature of the X70 strip. Furthermore, transverse cracking (cracking perpendicular to the main crack growth direction) was evident in the fracture surface of X70 strip which was correlated with microstructural banding of pearlite grains parallel to the rolling direction of the X70 strip. With a further increase in the hydrogen content to $4 \mathrm{ppm}$, fracture changed to a predominantly cleavage mode with characteristic features such as shear steps/ridges and river patterns for both TB and X70 strip. In addition, cracks were also observed in and normal to the direction of loading.

The MX70 strip, on the other hand, showed predominantly elongated shear/tear dimples on charging with $2 \mathrm{ppm} \mathrm{H}$. With an increase in the hydrogen content to $4 \mathrm{ppm}$, the fracture surface comprised of microvoids and dimples, as well as cleavage morphologies. Fracture acceleration sites (FAS) associated with large inclusions were also evident. The charged, as well as uncharged MX70 samples, consistently showed inclusions either within dimples or at centres of fast fracture sites. From the fractographs shown in Fig. 9, it is evident that the facets observed in the TB specimen are much coarser, corresponding to its larger grain size, than those in X70 and MX70 strips.

Fig. 10 shows fractographs of simulated coarse grained HAZ samples of X70 and MX70 samples before and after charging. The uncharged MX70 HAZ samples show a quasicleavage morphology with evidence of dimples, microvoids and cleavage facets, whereas 
only dimples and microvoids were observed on X70 HAZ samples. Shear dimple regions of the fractured X70 HAZ samples also showed remnants of fine microvoids that had coalesced to produce coarser shear dimples that were 20-50 $\mu \mathrm{m}$ wide. After charging to 2ppm, both these steels exhibited similar quasi-cleavage morphologies, with the $\mathrm{X} 70$ HAZ showing more cleavage and the MX70 HAZ more microvoids and dimples. On being charged to 4 ppm hydrogen both steels exhibited large cleavage facets with shear steps and tear ridges

\section{Discussion:}

Microstructural features such as reversible and irreversible traps present in the steel reduce the mobility of hydrogen towards the region of stress concentration ahead of the crack tip and thereby influence the susceptibility of the steel to hydrogen embrittlement. However, if the hydrogen concentration in the traps increases above the critical value for crack initiation, then traps can act as crack initiation sites. The type, amount, size and distribution of these traps affect the HIC susceptibility of the steel remarkably[2]. The observed differences in fracture toughness of the different samples studied here are discussed below in terms of the effects of grain size, microstructure and the type and distribution of precipitates.

\subsection{Effect of grain size:}

It is well established that grain refinement of metals and alloys increases the fracture toughness of the material. Consequently, the finer grain size of the X70 strip in the uncharged state results in a higher $\mathrm{J}_{\mathrm{Q}}$ value compared with the coarse grained normalised TB. Furthermore, it has also been reported that a refinement in grain size improves the resistance of materials to HIC[40-42]. However, when hydrogen is introduced into the material, grain boundaries can either increase hydrogen diffusion rates [43-45]or decrease it by acting as reversible hydrogen trapping sites at the nodes [46]. As the grain size decreases, although the mobility of hydrogen increases because of larger grain boundary area per unit volume, the higher density of nodes or junction points can act as potential traps for hydrogen atoms and lead to a reduction in its mobility. As a result of these two opposing effects, the hydrogen diffusion coefficient will be a maximum at an optimum 
grain size, as pointed out by Ichimura [11]. However, these authors have also reported that, for samples with smaller grain sizes the trapping effect of hydrogen at grain boundary nodes is significantly higher. Since the most significant microstructural difference between the normalized TB sample and the X70 strip was the ferrite grain size, it is likely that the coarser structure allowed more rapid diffusion of hydrogen to, and build up in, the stress concentrated zone ahead of the crack tip, thus facilitating crack propagation. The fine grained MX70 sample also exhibited higher $\mathrm{J}_{\mathrm{Q}}$ values than the TB sample, before and after hydrogen charging.

Moreover, it is also well established that dislocations act as effective traps for hydrogen and reduce their mobility. It is expected that the normalised ferrite-pearlite microstructure of the TB has a lower dislocation density than the hot rolled strips. Therefore, the combined effect of lower dislocation density and coarser grains for normalised TB results in its lower fracture toughness compared to the strips.

\subsection{Effect of microstructure:}

The hydrogen charged hot rolled X70 strip exhibited a higher $\mathrm{J}_{\mathrm{Q}}$ value as compared to the MX70 strip. A possible reason for this observation is that, pronounced microstructural banding of the ferrite-pearlite constituents was observed in the X70 strip. From electrochemical permeation experiments on ferrite-pearlite banded structures, Chan and co-workers [47-48] have shown that the effective diffusivities of hydrogen in specimens where the banding is perpendicular to the direction of hydrogen entry is an order of magnitude lower than in those specimens where hydrogen entry is along the direction of banding. Since the direction of the loading in the hot rolled X70 strip was perpendicular to the banded structure, the reduced mobility of hydrogen towards the crack tip could have resulted in a higher toughness compared with the MX70 strip which did not show any evidence of banding.

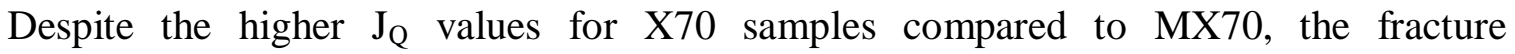
morphology in the presence of $\mathrm{H}$ indicated that fracture had occurred predominantly by cleavage. Despite this "brittle" mechanism of cracking, more energy was evidently consumed in the crack extension process than for the MX70 samples, which were 
ostensibly more "ductile" with the dominance of microvoids and shear dimples. However, following Beachem's hypothesis[49] that H induces cracking by facilitating the mechanism to which the microstructure is most susceptible, it is concluded that the shear strength of the MX70 is relatively low, allowing easy dislocation motion that results in the formation of microvoids and shear dimples. On the other hand, the significantly higher solute Mn content in the X70 may act as sufficient impediment to dislocation motion, that fracture initiates and progresses by cleavage, albeit with a higher expenditure of energy.

The simulated HAZ microstructures of both samples consisted predominantly of a microstructure of bainitic ferrite with aligned interphase martersite-austenite (MA) islands, that formed from coarse-grained austenite. The boundaries between the bainitic ferrite laths are low angle boundaries that do not impede crack propagation [50]. Fracture of bainitic steels along lath boundaries has been reported[51] and the MA constituent is known to provide initiation sites for fracture because of its high hardness and crack susceptibility [52]. Therefore, the combined effect of larger prior austenite grain size, the high hardness of these structures (Fig. 5), the presence of MA islands and the lower resistance to crack propagation results in lower $\mathrm{J}_{\mathrm{Q}}$ values for the HAZ simulated microstructures, both charged and uncharged, compared to the parent X70 or MX70 strips which consisted of mainly polygonal or quasi-polygonal ferrite.

When the samples are charged with hydrogen, the bainitic lath boundaries can trap large amounts of hydrogen[15]. Arafin and Szpunar [51] have observed extensive cracking in bainitic microstuctures and suggest that that the accumulation of significant amount of hydrogen at the bainitic lath boundaries can eventually lead to the separation of these interfaces and result in cracking when hydrogen concentration in these areas increases beyond a critical value. The diffusible hydrogen can then move ahead of the crack tip facilitating crack propagation. Therefore, in the presence of hydrogen, crack propagation is facilitated by the presence of bainitic lath interfaces, although the cracks may initiate at local MA regions in bainitic structures [51]. 
Consistent with the above observations, the simulated HAZ microstructures exhibited significantly lower $\mathrm{J}_{\mathrm{Q}}$ value compared to the X70 and MX70 parent materials, both in the charged and uncharged conditions

\subsection{Effect of precipitates:}

In non-cold worked steels like those used in this study, hydrogen can be trapped at interfaces between matrix and non-metallic particles or at the surface of voids and cracks etc. Several researchers have discussed the most effective trap sites. As the trap activation energies of the interfaces of non-metallic inclusions such as $\mathrm{MnS}$ and precipitates of $\mathrm{TiC}$ are high, they are regarded as strong irreversible traps for hydrogen[9, 53-54]. Furthermore, Pressouyre and Berstein [9] reported that incoherent precipitates are more effective than coherent TiC precipitates, whereas Takahashi et al. [53] and Valentini et al. [55] found fine coherent $\mathrm{TiC}$ particles and $\mathrm{Ti}(\mathrm{C}, \mathrm{N})$ precipitates to be stronger irreversible traps. According to Wei and Tsuzaki [56], NbC precipitates are stronger traps than $\mathrm{TiC}$ in tempered martensitic structures and in API X70 steels, subjected to electrochemical charging in $\mathrm{H}_{2} \mathrm{SO}_{4}$ solutions. Dong et al. [2] have reported that rather than nitrides of $\mathrm{Ti}$ and $\mathrm{Nb}$ being the main trap sites that cause HIC, coarser inclusions such as oxides play a dominant role. As regards, MnS inclusions, Pressouyre and Berstein [9]considered them to be strong irreversible trapping sites for hydrogen. However, other researchers have reported that $\mathrm{MnS}$ inclusion have moderate binding energies for hydrogen. Further, these inclusions have also been reported to act as reversible trapping sites [57]. The $\mathrm{J}_{\mathrm{Q}}$ values for the two strips are discussed below, taking into account relevant observations from the literature and the precipitate distribution observed in this study.

The current study show indicated that the MX70 strip had higher number densities of complex $(\mathrm{Ti}, \mathrm{Nb})(\mathrm{C}, \mathrm{N})$ precipitates and oxides of $\mathrm{Ca}$ and $\mathrm{Al}$ compared to the $\mathrm{X} 70$ strip (Fig. 3). As mentioned above, several authors report that the fine carbonitrides can act as strong traps for hydrogen and significantly reduce the mobility of hydrogen thereby increasing its resistance to HIC [58-60]. However, the TPB tests results show that MX70 strip charged to $2 \mathrm{ppm}$ and $4 \mathrm{ppm}$ hydrogen exhibited a lower $\mathrm{J}_{\mathrm{Q}}$ than the $\mathrm{X} 70$ strip. This can be rationalized in terms of the size distribution of the different precipitates in the two steels. The carbonitride precipitates in MX70 strip showed a broad distribution in size 
with a long tail and although there were a large number of fine carbonitride precipitates, some large precipitates, like the large particle shown in Fig. 11, which was about $10.5 \mu \mathrm{m}$ in diameter, were also present. Moreover, the MX70 strip had double the number of oxide inclusions compared to X70 strip with most of the inclusions having diameters greater than $2 \mu \mathrm{m}$. Dong et al. [2] observed cracks originating from large inclusions of $\mathrm{Ca}$ and $\mathrm{Al}$, rather than $\mathrm{Ti}$ or $\mathrm{Nb}$ carbonitrides. Therefore, they suggested that the larger diameters of the oxides (2-3 $\mu \mathrm{m}$ in diameter) can attract more hydrogen towards them than fine carbonitrides and that coarse oxide inclusions play a dominant role in HIC. Therefore, the lower $\mathrm{J}_{\mathrm{Q}}$ values observed for the charged MX70 strip may be attributable to the presence of coarse oxide inclusions and/or $(\mathrm{Ti}, \mathrm{Nb})(\mathrm{C}, \mathrm{N})$ precipitates present in these samples. These particles could effectively trap hydrogen to the critical level to induce particle cracking or interfacial decohesion, leading to local void growth and coalescence or to cleavage fracture. This hypothesis is supported by evidence of inclusions/precipitates at the centres of dimples and fast fracture sites, see for example Fig. 11.

The number densities of MnS precipitates are almost the same in both of these strips. However, it can be seen from Fig. (4b) that the distribution of the aspect ratios of $\mathrm{MnS}$ precipitates for the MX70 specimen has an extremely long tail with some MnS precipitates exhibiting very high aspect ratios of up to 20:1. Domizzi et al. [11] have reported that the presence of even a small number of very elongated inclusions can result in reduced HIC resistance. So this factor could contribute to the lower HIC resistance of the MX70 steel. However, in this study, the long MnS inclusions were aligned perpendicular to the loading direction during the TPB tests and therefore it is suggested that they would not have any significant detrimental affect on $\mathrm{J}_{\mathrm{Q}}$ of the MX70 strip. Rather, it is considered that the lower $\mathrm{J}_{\mathrm{Q}}$ values compared to $\mathrm{X} 70$ are due to the present of coarser inclusions of oxides or carbonitride precipitates, their susceptibility to cracking/decohesion in the presence of hydrogen and the reduced resistance to dislocation motion because of the much lower concentration of solute $\mathrm{Mn}$. 


\section{Conclusions:}

1. The hot rolled $X 70$ steel consistently exhibited a slightly higher $\mathrm{J}_{\mathrm{Q}}$ than the $\mathrm{MX70}$ strip before and after hydrogen charging.

2. The coarse grained, normalised $\mathrm{TB}$ showed lower $\mathrm{J}_{\mathrm{Q}}$ values than both hot rolled strip steels.

3. Increasing the hydrogen content lowered the fracture performance, with the samples exhibiting an approximately linear dependence of $\mathrm{J}_{\mathrm{Q}}$ on $\mathrm{H}$.

4. The fracture surfaces of $X 70$ and MX70 were characterised by more ductile modes of cracking: microvoids, dimples with no hydrogen; and more brittle modes: quasi-cleavage and cleavage for 2 and 4 ppm hydrogen.

5. Although the fracture surface of MX70 showed that shear mechanisms were dominant, it exhibited lower $\mathrm{J}_{\mathrm{Q}}$ values because of the presence of a higher volume fraction of coarse oxide and carbonitrides that promoted void growth and/or cleavage, together with a reduced shear strength due to the lower Mn content.

6. Simulated CGHAZ structures for both the standard and medium Mn steels showed low $\mathrm{J}_{\mathrm{Q}}$ values which decreased with increasing hydrogen. There was little effect due to the difference in Mn content. The coarser prior austentite grain size and the relatively hard banitic-ferrite structure with M/A islands resulted in a marked decrease in toughness both with and without hydrogen.

\section{Acknowledgements}

This study was conducted as part of Australian Research Council (ARC) Linkage grant with BlueScope as the industrial partner. The authors would like to thank ARC and BlueScope for their financial support. 


\section{References}

[1] J.G. Williams, Materials Forum, 31 (2007) 1-10.

[2] C.F. Dong, X.G. Li, Z.Y. Liu, Y.R. Zhang, Journal of Alloys and Compounds, 484 (2009) 966-972.

[3] F. Huang, J. Liu, Z.J. Deng, J.H. Cheng, Z.H. Lu, X.G. Li, Mater. Sci. Eng. A, 527 6997-7001.

[4] C.F. Dong, Z.Y. Liu, X.G. Li, Y.F. Cheng, International Journal of Hydrogen Energy, 34 (2009) 9879-9884.

[5] S.K. Yen, I.B. Huang, Materials Chemistry and Physics, 80 (2003) 662-666.

[6] H.B. Xue, Y.F. Cheng, Corrosion Science, 53 1201-1208.

[7] E. Villalba, A. Atrens, Engineering Failure Analysis, 16 (2009) 164-175.

[8] S.M. Lee, J.Y. Lee, Acta metall., 35 (1987) 2695-2700.

[9] Pressouyre Gm, I. Bernstein, Metall. Trans. A, 10 (1978) 1571.

[10] F.G. Wei, K. Tsuzaki, Metall. Trans. A, 35A (2004) 3155-3163.

[11] G. Domizzi, G. Anteri, J. Ovejero-García, Corrosion Science, 43 (2001) 325-339.

[12] T.Y. Jin, Z.Y. Liu, Y.F. Cheng, International Journal of Hydrogen Energy, 35 8014-8021.

[13] W.K. Kim, S.U. Koh, B.Y. Yang, K.Y. Kim, Corrosion Science, 50 (2008) 33363342.

[14] S.S. Nayak, R.D.K. Misra, J. Hartmann, F. Siciliano, J.M. Gray, Mater. Sci. Eng. A, 494 (2008) 456-463.

[15] G.T. Park, S.U. Koh, H.G. Jung, K.Y. Kim, Corrosion Science, 50 (2008) 18651871.

[16] R.A. Carneiro, R.C. Ratnapuli, V. De Freitas Cunha Lins, Mater. Sci. Eng. A, 357 (2003) 104-110.

[17] S. Serna, H. Martínez, S.Y. López, J.G. González-Rodríguez, J.L. Albarrán, International Journal of Hydrogen Energy, 30 (2005) 1333-1338.

[18] S. Shanmugam, R.D.K. Misra, J. Hartmann, S.G. Jansto, Mater. Sci. Eng. A, 441 (2006) 215-229.

[19] S. Shanmugam, N.K. Ramisetti, R.D.K. Misra, J. Hartmann, S.G. Jansto, Mater. Sci. Eng. A, 478 (2008) 26-37.

[20] E. Lunarska, Y. Ososkov, Y. Jagodzinsky, International Journal of Hydrogen Energy, 22 279-284.

[21] Y. Zhong, F. Xiao, J. Zhang, Y. Shan, W. Wang, K. Yang, Acta Mater., 54 (2006) 435-443.

[22] M.-C. Zhao, K. Yang, Scripta Materialia, 52 (2005) 881-886.

[23] M.-C. Zhao, K. Yang, Y. Shan, Mater. Sci. Eng. A, 335 (2002) 14-20.

[24] K. Junhua, Z. Lin, G. Bin, L. Pinghe, W. Aihua, X. Changsheng, Materials \&amp; Design, 25 (2004) 723-728.

[25] A. Contreras, A. Albiter, M. Salazar, R. Pérez, Mater. Sci. Eng. A, 407 (2005) 4552.

[26] B. Beidokhti, A. Dolati, A.H. Koukabi, Mater. Sci. Eng. A, 507 (2009) 167-173.

[27] M.-C. Zhao, K. Yang, F.-R. Xiao, Y.-Y. Shan, Mater. Sci. Eng. A, 355 (2003) 126-136.

[28] J.G. Williams, in: Thermomechanical Proceeding of Steel, Padua Italy, 2008.

[29] A. Takahashi, M. Iino, ISIJ International, 36 (1996) 235-240. 
[30] ASTM E813-89: Standard Method for JIC, A Measure of Fracture Toughness p. 630-634.

[31] ASTM E647 - 00 Standard test method for measurement of fatigue crack growth rates.

[32] in.

[33] B. Fang, J.Q. Wang, E. Han, Z. Zhu, W. Ke, - Influence of strain rate on the stress corrosion cracking of X70 pipeline steel in dilute near-neutral $\mathrm{pH}$ solutions, in: S.A. Shipilov, R.H. Jones, J.M. Olive, R.H.J.J.M.O. R.B. RebakA2 - S.A. Shipilov, R.B. Rebak (Eds.) Environment-Induced Cracking of Materials, Elsevier, Amsterdam, 2008, pp. 303-311.

[34] R. Gou, Y. Zhang, X. Xu, L. Sun, Y. Yang, NDT \&amp; E International, 44 (2011) 387-393.

[35] H. Sayyed H, International Journal of Pressure Vessels and Piping, 85 (2008) 879-884.

[36] G.A. Zhang, Y.F. Cheng, Electrochimica Acta, 55 (2009) 316-324.

[37] G.A. Zhang, Y.F. Cheng, Corrosion Science, 51 (2009) 1714-1724.

[38] P. Liang, X. Li, C. Du, X. Chen, Materials \&amp; Design, 30 (2009) 1712-1717.

[39] F. Rivalin, A. Pineau, M. Di fant, J. Besson, Engineering Fracture Mechanics, 68 (2000) 329-345.

[40] I.M. Bernstein, A.W. Thompson, Int. Metals Reviews, 21 (1976) 269-287.

[41] W.M. Cain, A.R. Troiano, Petrol eng, 37 (1965) 78.

[42] A.W. Thompson, I.M. Bernstein, Advances in corrosion science and technology', Plenum Press, New York, 1980.

[43] A.Kimura, H.K. Birnbaum, Acta Mater., 36 (1988) 757.

[44] R.D. Calder, T.S. Elleman, K. Verghese, Nucl. Mater, 46 (1973) 46.

[45] T.Tsuru, R.M. Latanision, Scripta Metall, 16 (1982) 575.

[46] M. Ichimura, Y. Sasajima, M. Imabayashi, Materials Transactions, 32 (1991) 1109-1114.

[47] L. Tau, S.L.I. Chan, Materials Letters, 29 (1996) 143-147.

[48] H.-L. Lee, S.L.-I. Chan, Mater. Sci. Eng. A, 142 (1991) 193-201.

[49] C.D. Beachem, METALLURGICAL TRANSACTIONS, 3 (1972) 451.

[50] F.B. Pickering, Physical Metallurgy and the Design of Steels, Guildford, Surrey, Great Britain, 1978.

[51] M.A. Arafin, J.A. Szpunar, Corrosion Science, 51 (2009) 119-128.

[52] S. Lee, B.C. Kim, D.Y. Lee, Scripta Metallurgica, 23 (1989) 995-1000.

[53] I. Takahashi, Y. Matsumoto, T. Tanada, in: JIMIS-2, Minakami, Tokyo, Japan, 1979, pp. 285-289.

[54] M.F. Stevens, I.M. Bernstein, Metall. Trans. A, 20A (1989) 909-919.

[55] R. Valentini, A. Solina, S. Matera, P.D. Gregorio, Metall. Trans. A, 27A (1996) 3773-3779.

[56] F.-G. Wei, K. Tsuzaki, in: International Hydrogen Conference (ASM International) 2009, pp. 456-463.

[57] M. Garet, A.M. Brass, C. Haut, F. Guttierez-Solana, Corrosion Science, 40 (1998) 1073-1086.

[58] M.-C. Zhao, M. Liu, A. Atrens, Y.-Y. Shan, K. Yang, Mater. Sci. Eng. A, 478 (2008) 43-47. 
[59] E. Ramírez, J.G. González-Rodriguez, A. Torres-Islas, S. Serna, B. Campillo, G. Dominguez-Patiño, J.A. Juárez-Islas, Corrosion Science, 50 (2008) 3534-3541.

[60] C. Hurtado Noreña, P. Bruzzoni, Mater. Sci. Eng. A, 527 (2010) 410-416. 


\section{LIST OF TABLES}

Table 1. Chemical composition of the steels (wt. \%).

Table 2. Experimental values of fracture toughness, $\mathrm{J}_{\mathrm{Q}}$ before and after charging to 2 and 4 ppm hydrogen. 


\section{FIGURE CAPTIONS}

Fig. 1. Schedule for thermomechanical simulation of coarse grained structure produced during in-service pipeline welding.

Fig. 2. Optical micrographs of samples (a) TB, (b) X70, (c) MX70, (d) X70 HAZ and (e) MX70 HAZ.

Fig. 3. Plots showing the number and type of (a) nitrides, (b) sulphides and (c) oxides present in the two steels.

Fig. 4. Plots showing the mean values and distribution of (a) size of $(\mathrm{Ti}, \mathrm{Nb})(\mathrm{C}, \mathrm{N})$ precipitates, (b) aspect ratio of $\mathrm{MnS}$ and (c) size of oxides of $\mathrm{Ca}$ and $\mathrm{Al}$.

Fig. 5. Hardness profiles of X70 and MX70.

Fig. 6. J-R curves before and after charging to 2 and 4 ppm hydrogen (a) TB, (b) X70 and (c) X70 HAZ samples.

Fig. 7. J-R curves before and after charging to 2 and 4 ppm hydrogen (a) MX70 (b) MX70 HAZ samples.

Fig. 8. Variation of $\mathrm{J}_{\mathrm{Q}}$ values with hydrogen content for different samples.

Fig. 9. SEM fractographs of fracture surfaces of the samples before and after charging (a), (b), (c) TB after 0, 2, 4 ppm H respectively, (d), (e), (f) X70 strip after 0, 2, 4 ppm H respectively, (g), (h), (i) X70 HAZ after 0, 2 and 4 ppm $\mathrm{H}$ respectively.

Fig. 10. SEM fractographs of fracture surfaces of the samples before and after (a), (b), (c) MX70 after 0, 2, 4 ppm H respectively, (d), (e), (f) MX70 HAZ after 0, 2 and 4 ppm H respectively.

Fig. 11. SEM fractographs of MX70 samples showing large carbonitride particles. 
Table 1: Chemical composition of the steels (wt.\%)

\begin{tabular}{|c|c|c|c|c|c|c|c|c|c|c|c|c|c|c|c|}
\hline & $\mathbf{C}$ & $\mathbf{P}$ & $\mathbf{M n}$ & $\mathbf{S i}$ & $\mathbf{N i}$ & $\mathbf{C r}$ & $\mathbf{M o}$ & $\mathbf{C u}$ & $\mathbf{A l}$ & $\mathbf{N b}$ & $\mathbf{T i}$ & $\mathbf{V}$ & $\mathbf{S}$ & $\mathbf{N}$ & $\mathrm{C}_{\mathrm{E}}$ \\
\hline $\mathbf{X 7 0}$ & 0.074 & 0.012 & 1.14 & 0.22 & 0.024 & 0.029 & 0.1 & 0.023 & 0.019 & 0.06 & 0.02 & 0.002 & 0.002 & 0.0041 & 0.256 \\
\hline M X70 & 0.085 & 0.01 & 0.5 & 0.19 & 0.018 & 0.26 & 0.11 & 0.011 & 0.04 & 0.059 & 0.035 & 0.003 & 0.002 & 0.0054 & 0.276 \\
\hline
\end{tabular}


Table 2: Experimental values of fracture toughness, $\mathrm{J}_{\mathrm{Q}}$ before and after of charging to 2 and 4 ppm hydrogen

\begin{tabular}{|c|c|c|c|c|c|}
\hline $\begin{array}{l}\text { Hydrogen } \\
\text { content (ppm) }\end{array}$ & X70 TB & X70 strip & MX70 strip & $\begin{array}{l}\text { X70 strip } \\
\text { HAZ }\end{array}$ & $\begin{array}{l}\text { MX70 strip } \\
\text { HAZ }\end{array}$ \\
\hline $\mathbf{0}$ & 162 & 261 & 229 & 155 & 163 \\
\hline 2 & 125 & 222 & 192 & 110 & 117 \\
\hline 4 & 101 & 168 & 152 & 48 & 55 \\
\hline
\end{tabular}




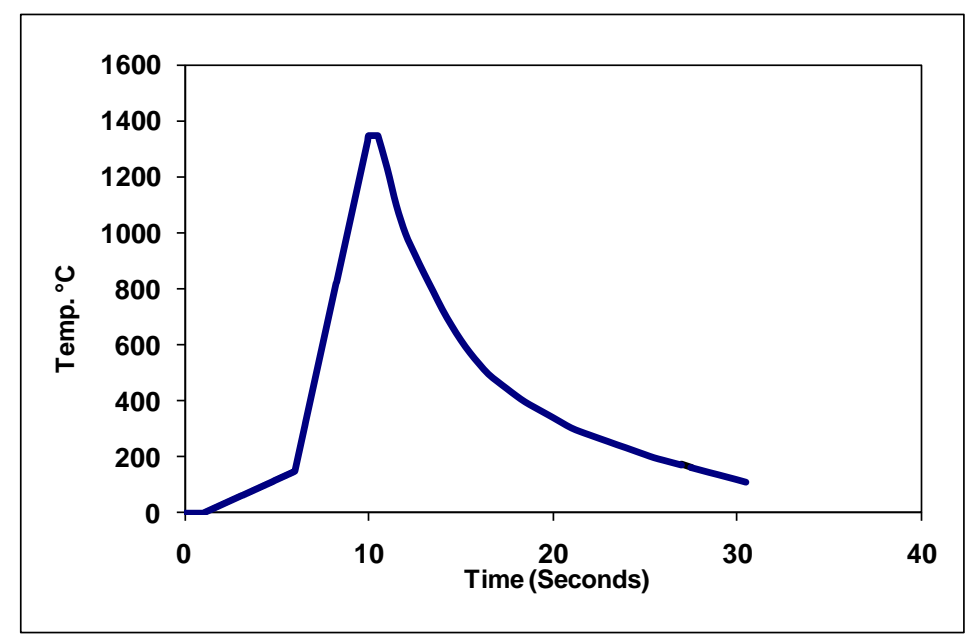

Fig. 1. Schedule for thermomechanical simulation of coarse grained structure produced during in-service pipeline welding. 

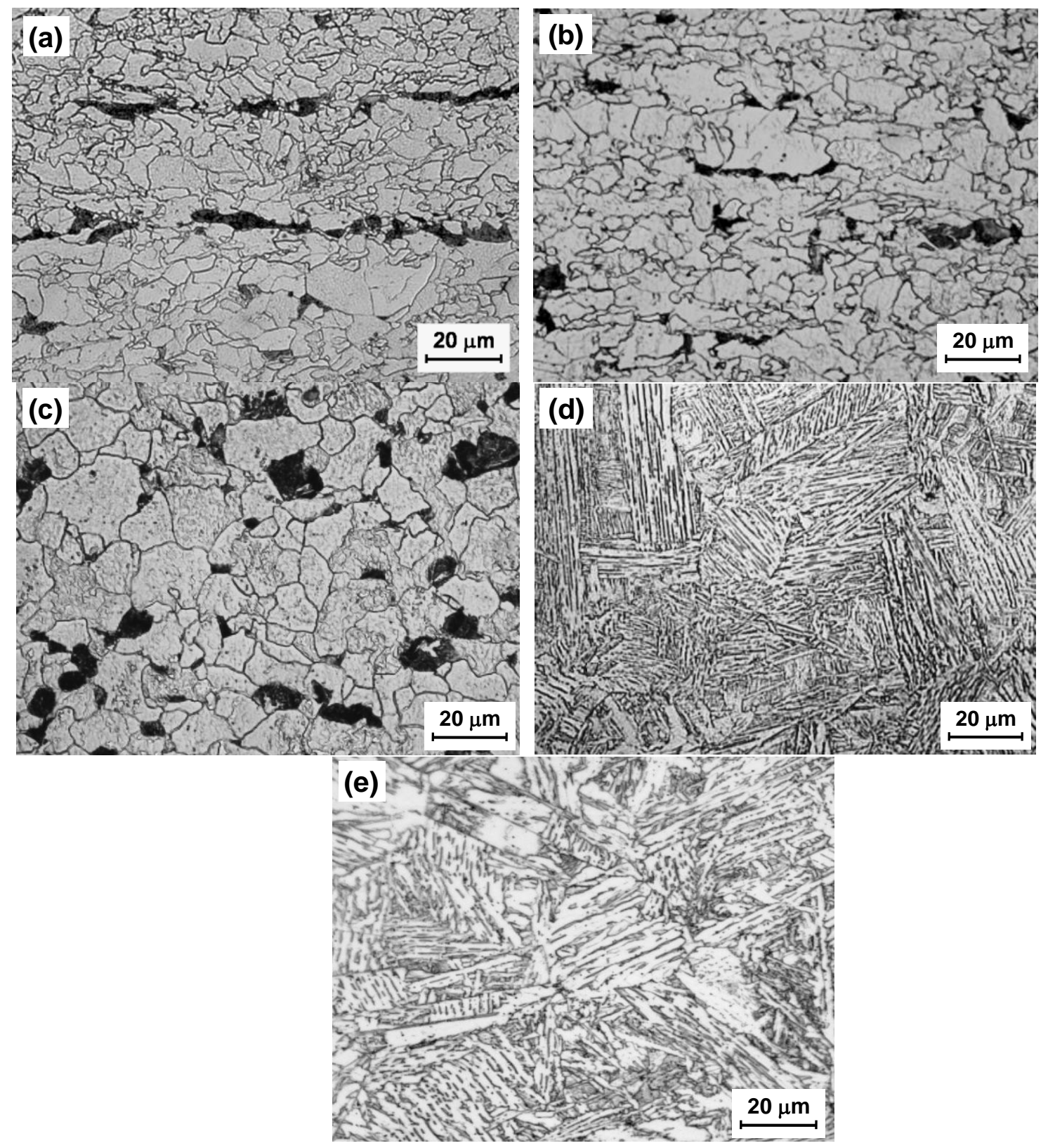

Fig. 2. Optical micrographs of samples (a) TB, (b) X70, (c) MX70, (d) X70 HAZ and (e) MX70 HAZ. 

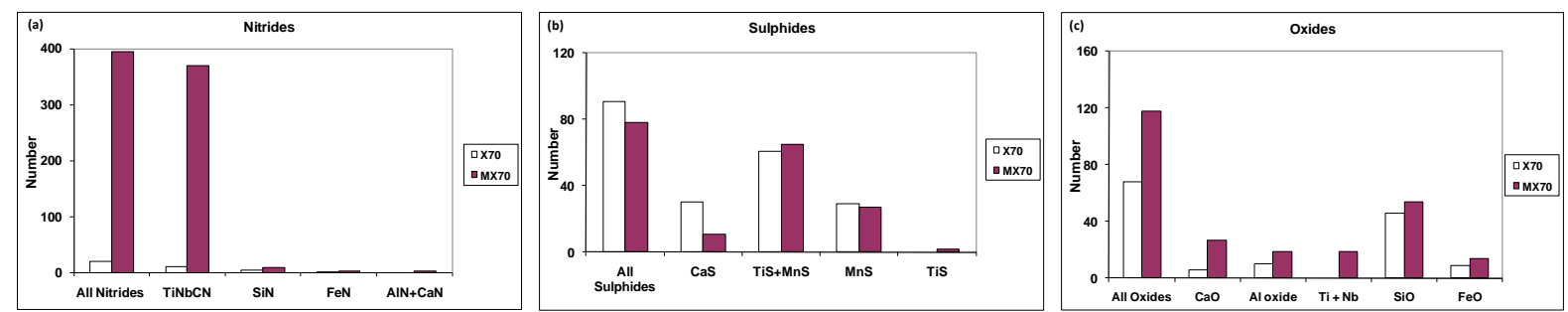

Fig. 3. Plots showing the number and type of (a) nitrides, (b) sulphides and (c) oxides present in the two steels. 

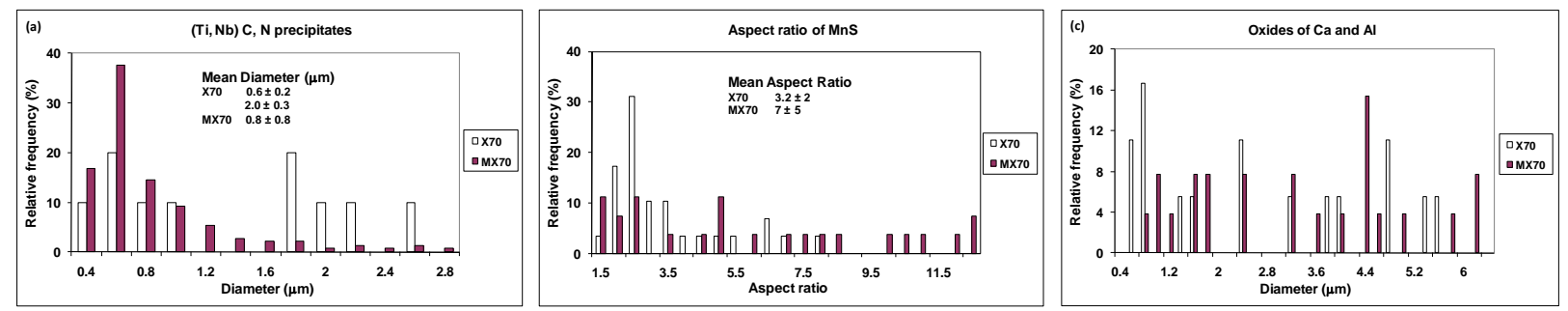

Fig. 4. Plots showing the mean values and distribution of (a) size of $(\mathrm{Ti}, \mathrm{Nb})(\mathrm{C}, \mathrm{N})$ precipitates, (b) aspect ratio of $\mathrm{MnS}$ and (c) size of oxides of $\mathrm{Ca}$ and $\mathrm{Al}$. 


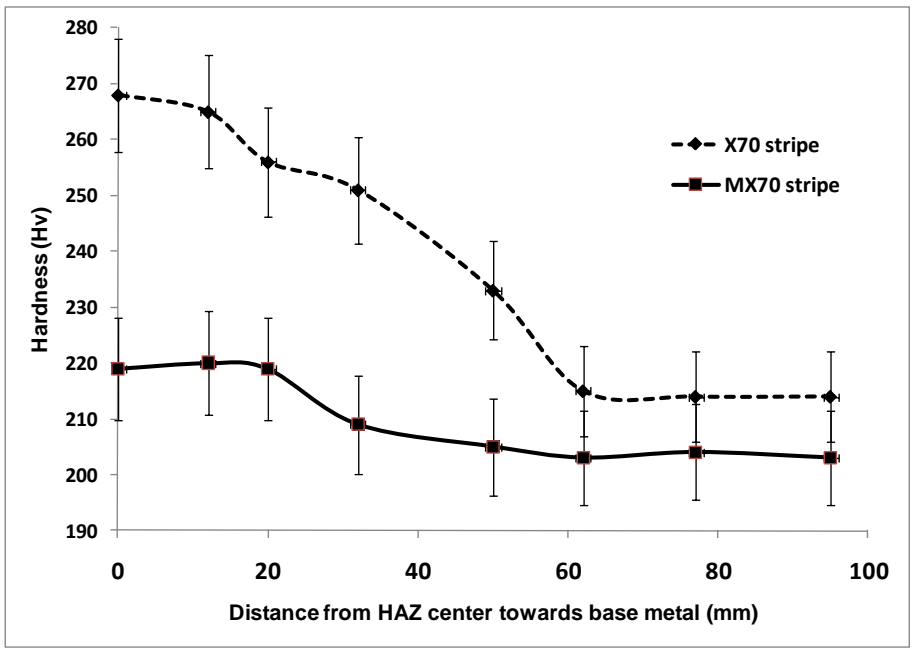

Fig. 5. Hardness profiles of X70 and MX70. 
Fig. 6. J-R curves before and after charging to 2 and 4 ppm hydrogen (a) TB, (b) X70 and (c) X70 HAZ samples.
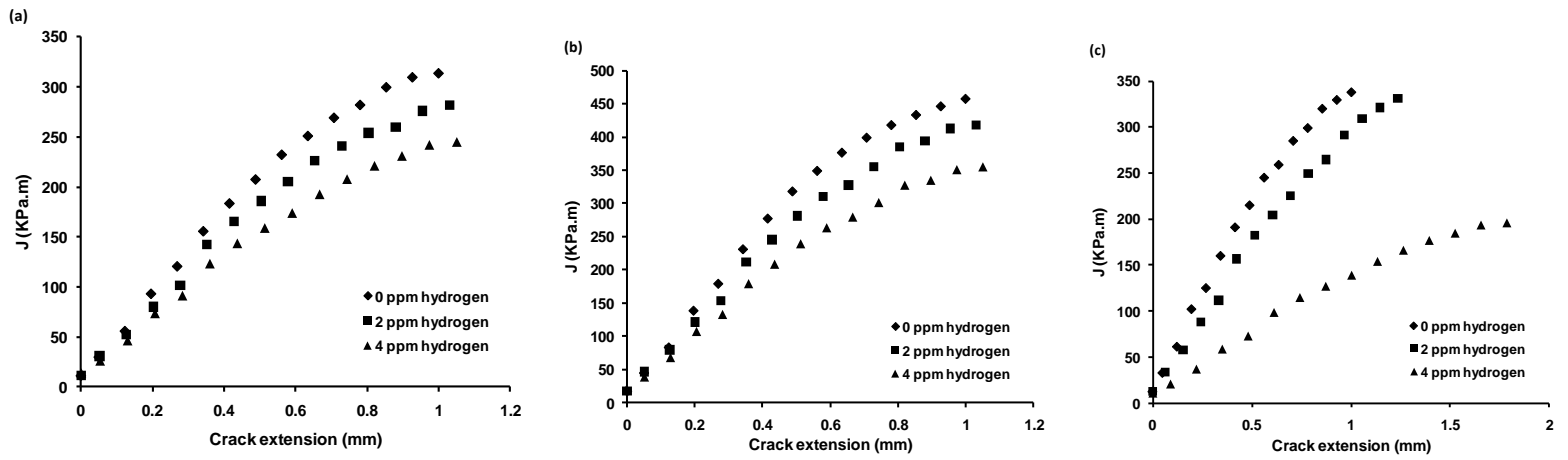
Fig. 7. J-R curves before and after charging to 2 and 4 ppm hydrogen (a) MX70 (b) MX70 HAZ samples.
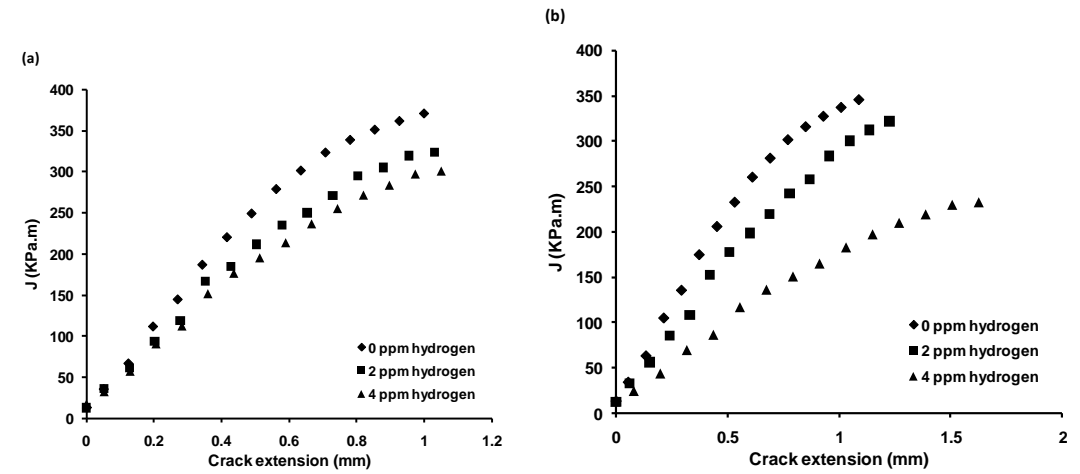


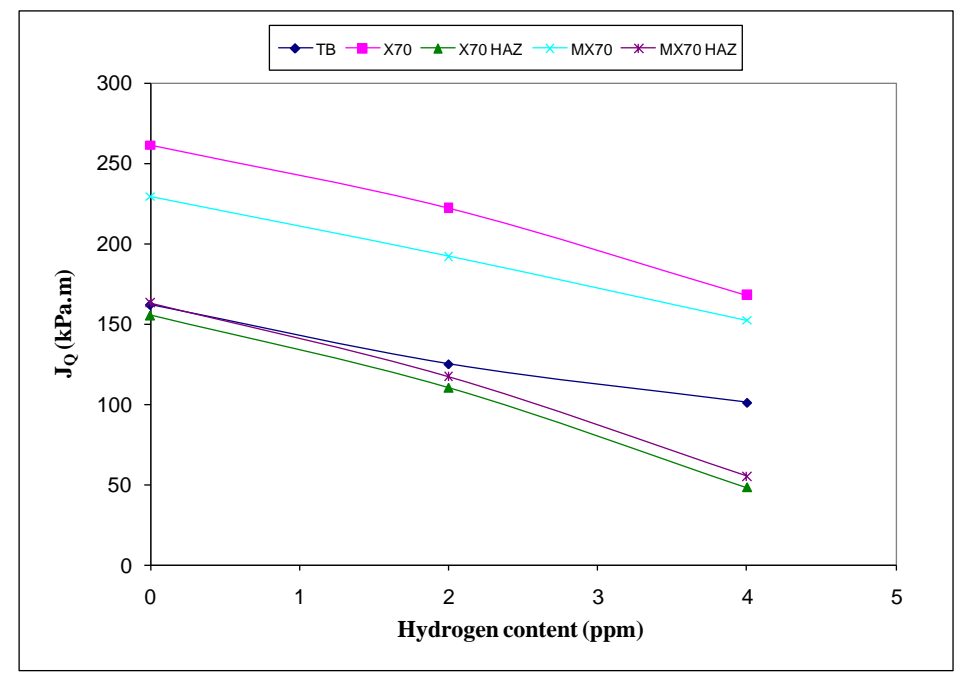

Fig. 8. Variation of $\mathrm{J}_{\mathrm{Q}}$ values with hydrogen content for different samples. 

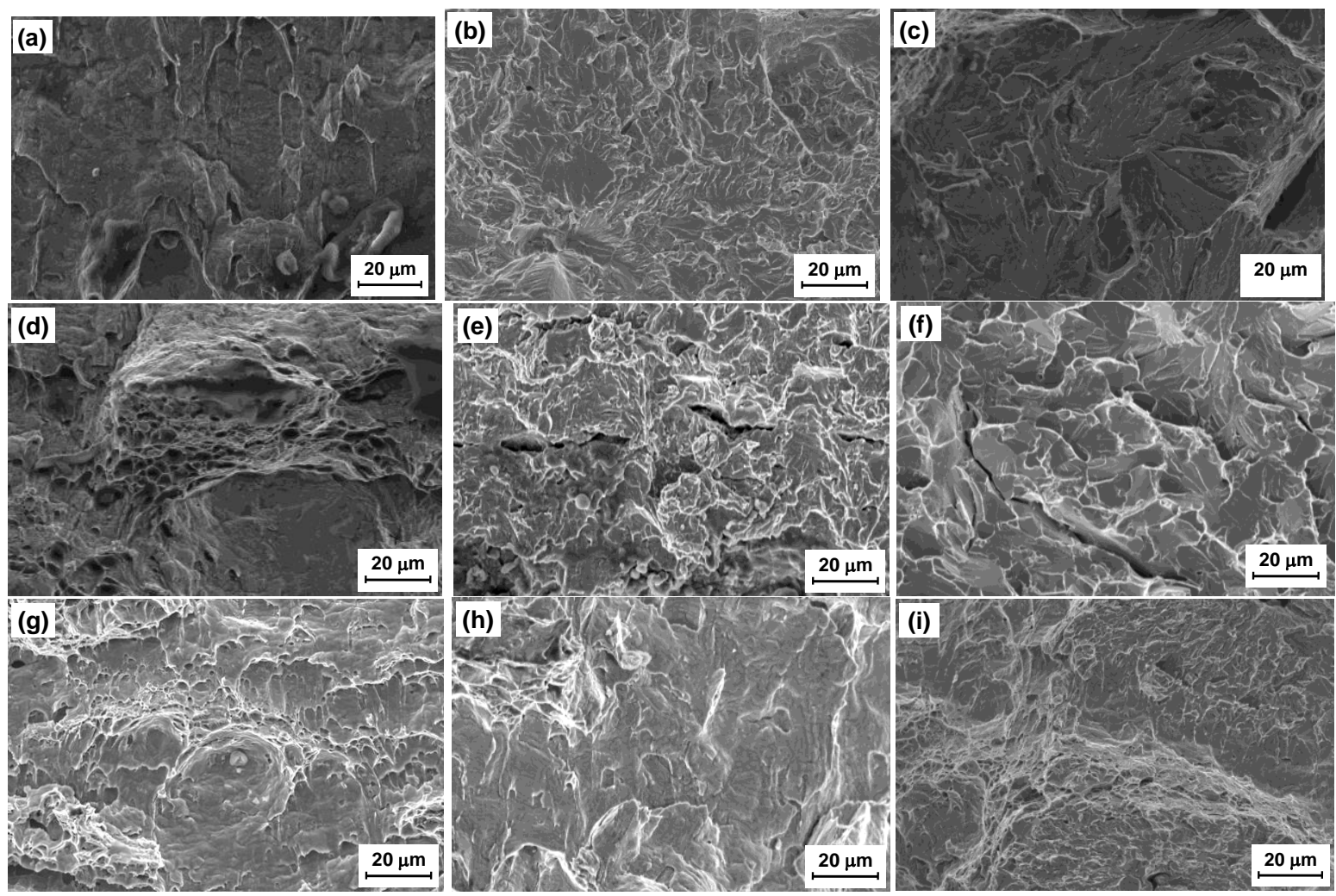

Fig. 9. SEM fractographs of fracture surfaces of the samples before and after charging (a), (b), (c) TB after 0, 2, 4 ppm $\mathrm{H}$ respectively, (d), (e), (f) X70 strip after 0, 2, 4 ppm $\mathrm{H}$ respectively, (g), (h), (i) X70 HAZ after 0, 2 and 4 ppm H respectively. 

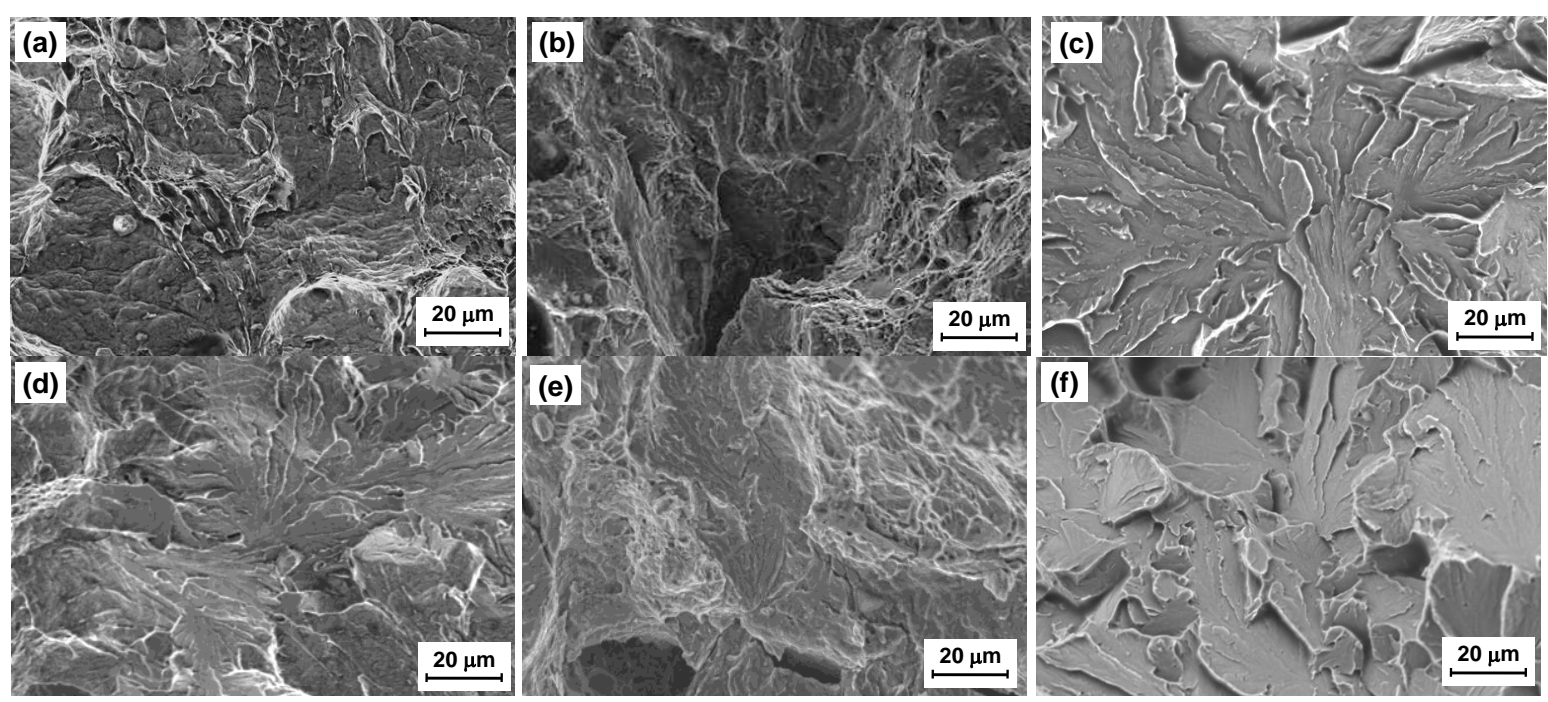

Fig. 10. SEM fractographs of fracture surfaces of the samples before and after (a), (b), (c) MX70 after 0, 2, 4 ppm H respectively, (d), (e), (f) MX70 HAZ after 0, 2 and 4 ppm H respectively. 

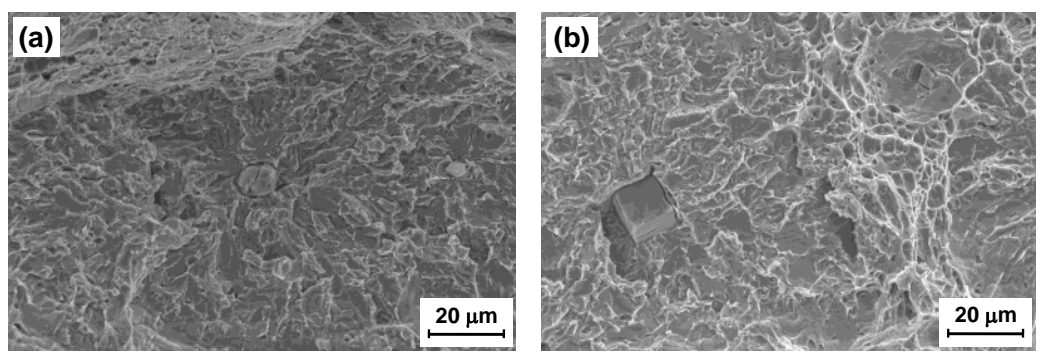

Fig. 11. SEM fractographs of MX70 samples showing large carbonitride particles. 